\title{
Sales Executives' Reward Attitude Survey in the International Company and their Socio- Economic Consequences on the Sales Performance in Global Markets
}

\author{
Gabriela Polakova ${ }^{l, *}$ \\ ${ }^{1}$ VSB-Technical University of Ostrava, Faculty of Economics, Department of Management, Sokolska \\ trida 33, 70200 Ostrava 1, Czech Republic
}

\begin{abstract}
.
Research background: As a universal rule applicable worldwide, the salary satisfaction and employees' financial well-being, in general, are ones of key drivers in ensuring corporate business goals and performance in global markets.

Purpose of the article: The aim is to find out how sales executives are satisfied with their financial well-being and earnings gained in one international company making business worldwide. The analyzed company needs to support sales executives' motivation to meet sales goals and positively influence their engagement in making business all over the world, and thus globally improve corporate performance.

Methods: The methodology of the procedure begins with the formulation of research questions. Subsequently, a questionnaire is compiled, the basic and sample of respondents are identified, and a questionnaire survey is conducted. The processing of the obtained data is performed using statistical methods (software IBM SPSS statistics) when the results are processed using frequency and contingency tables, graphs, and verbal description. The final step is answering research questions.

Findings \& Value added: The data include general sales executives' reward attitudes, their subjective feelings, and opinions if their pays reflect their sales performance in international business or not. Such survey usefully provides relevant information to competent decision-makers about sales executives' financial satisfaction and well-being and gives them a good background to ensure that payment will be in such a competitive level of market price that will attract and retain the people the organization needs for retaining current global business operations and for searching new business challenges around the world.
\end{abstract}

Keywords: Salary Satisfaction; Reward Attitude Survey; Financial Wellbeing; Sales Executives; Global Markets.

JEL Classification: $M 12$; M52; M29

\footnotetext{
* Corresponding author: gabriela.polakova@post.cz
} 


\section{Introduction and literature review}

Rewards management plays a critical role in the motivation and retention of highquality staff and can play an important role in addressing the issue of supporting employee performance. There is evidence that adequate rewards play a crucial role in regulating employee turnover. In the new global economy, financial wellbeing has become a central issue for employee satisfaction. There is a large volume of published studies describing the role of financial rewards on employees' performance. The existing literature on rewards management is extensive and focuses particularly on influence of money, benefits, good interpersonal relationships in the workplace and working environment on employee satisfaction. In the professional literature, the issue of employee rewards is solved, for example, by Armstrong and Stephens [1], who state: "Financial incentives and rewards can motivate. People need money and therefore want money. It can motivate but it is not the only motivator." They suggest that money can act as a goal that people generally strive for, and also can be a symbol which indicates the recipient's value to the organization. Money motivates because it is linked directly or indirectly with the satisfaction of many needs. Pfeffer [2] contends that: "People do work for money - but they work even more for meaning in their lives. In fact, they work to have fun. Companies that ignore this fact are essentially bribing their employees and will pay the price in lack of loyalty and commitment." He believes that pay cannot substitute for a working environment "high on trust, fun and meaningful work". According to Gupta and Shaw [3] employees will do the things for which they are rewarded; it also means that they ignore the things for which they are not rewarded. Gupta and Jenkins [4] state that organizations use pay to achieve their objectives (presumably the recruitment and retention of high-performing individuals) and that employees tailor their behaviour to maximize their monetary rewards. As Lawler [5] points out, people's feelings about the adequacy of their pay are based upon comparisons they make between their own and others'. External market comparisons are the most critical because they are the ones that strongly influence whether individuals want to stay with the organization. Money is the number one stressor in human lives [6], money fights are qualitatively worse than other kinds of fights [7], financial stress is related to poor mental health [8], and financial stress affects our physical health [9]. There is a clear association between a person's financial health and his/her emotional and physical health and wellbeing [10]. Money can have negative impact on individuals', couples', and families' functioning [11]. Syrén et al. [12] found positive bivariate associations between income and mental well-being and its dimensions: emotional, psychological, and social well-being and reversed depression. Gross monthly income is statistically significantly associated with reversed depression, and experienced household finances are related to mental well-being and its emotional wellbeing dimension [12]. Lucas et al. [13] is developing an empirical database to better understand how employers offer financial wellness initiatives, how workers use them, and what impact they have on workers' overall financial wellbeing. Management needs to introduce dynamic reward and recognition mechanisms to extend intangible support, and career advancement opportunity to increase trust and confidence of employees. According to Benitez et al. [14], results showed that work groups with a more positive distribution of well-being profiles, that is, with a greater proportion of employees with high levels of job satisfaction combined with low levels of burnout (emotional exhaustion and cynicism), significantly outperformed work groups with a less favourable internal distribution of well-being profiles. The findings point to a mutual gains model [15] whereby high employee job satisfaction, coupled with low burnout (emotional exhaustion and cynicism), positively contributes to service quality and ultimately, therefore, to organizational performance. In other words, [14] results indicate that employee well-being is positively related to the delivery of service quality, as 
perceived by customers. Hager [16] identifies and synthesizes what is known about links between job meaningfulness, work-engagement and psychological well-being of employees. He argued that creating meaningfulness at work, is closely related to workengagement and well-being and is essential for positive work outcomes and healthy employees. If employees find meaningfulness, and as long as they can see significance in their work-tasks, they are ready for maximum achievements and personal sacrifices. Meaningfulness can be seen as the origin from which the mentioned power rises that stimulates people, if motivation is depleted whilst the goal has not yet been reached. Mindfulness has exploded in popularity with the development of multiple health-based programmes. Organizations have looked to mindfulness as a possible tool to enhance wellbeing and performance [17]. Ghazalli et al. [18] investigate the effects of psychological factors on the financial wellbeing. Celma et al. [19] analyse the effectiveness of several practices of HRM which influence employees' wellbeing at work: job stress, job satisfaction and trust in management. In general, higher job quality increases employees' wellbeing at work. Liu et al [20] examined the impact of resilience training on personal resilience and four broad categories of dependent variables, including (1) mental health and subjective will-being outcomes, (2) psychosocial outcomes, (3) physical/biological outcomes, and (4) performance outcomes. They identified that resilience training can improve personal resilience and is a useful means of developing mental health and subjective well-being in employees, such as stress, depression, anxiety, and negative mood/affect/emotion. According to Bui et al. [21] satisfaction over material rewards mediates the relationship between harmonious workplace climate and employee altruistic behaviour. Both perceived organizational politics and career ambition moderate the mediated effect of harmonious workplace climate on employee altruistic behaviour via satisfaction over rewards. [22]. Practice of payroll systems is based on the compromise. Usually it is a compromise between the expectations of employees and the financial capacity of the employer or as a result of interaction between the market forces, supply and demand. Depending on the circumstances, there is a risk of distortions resulting in too low or too high salaries or an incorrect pay relationship in the organization. As a result, the welfare of the employees is reduced, or the employer's financial balance is at risk.

\section{Methods and data}

One of the most well-known tools for assessing employee reward attitude is a questionnaire survey. This quantitative method of public opinion research offers an effective way of determining employee satisfaction. The questionnaire survey was selected for its reliability and validity. The advantage of using questionnaire is simplicity, speed, and practical way of identifying and characterising a public opinion and attitude. The questionnaire survey was conducted in July 2020 and took place directly in the analysed company in the form of anonymous printed questionnaires. The design of the questionnaires was based on 20 questions. The questions asked participants to rate if they agreed or disagreed with a statement. The nominal variable takes only two possible values (yes/no), so it is a dichotomous variable. 20 sales executives working in the business department of the analysed international company were included and recruited for this study and represent the basic. A total of 14 respondents (70\%) answered who represent the sample from which the obtained results are used to make a judgment about the basic. A smaller sample was obtained because of the expected difficulty in obtaining their subjective opinions and attitudes due to the current situation with the intensive ongoing staff reductions due to the global financial impact of the coronavirus pandemic. In an attempt to make each interviewee feel as comfortable as possible, the questionnaires were completed anonymously. Statistical analysis was performed using SPSS software (version 20). 
Descriptive data were generated for all variables. The results were processed using frequency and contingency tables, graphs, and verbal description. A case-study approach was chosen to evaluate the effectiveness of current reward system, to gain a detailed understanding on sales executives' financial wellbeing and to determine the factors that affect sales executives' motivation to improve their performance.

\subsection{Case study}

Case is about organization where the development or improvement of reward management policies and practices is necessary to enhance organizational performance, and where there are specific issues and problems concerning current reward management practices which need to be dealt with. The case is about problem solving and the introduction and management of change. The analysed company is a large-sized society based in the Czech Republic and covering mainly the European, US and Canadian market and the Middle East market. It has been run on very traditional lines with a high degree of bureaucracy, a generally inflexible approach to operations and people, and a strong culture of command and control. Little attention has been given to employees' satisfaction, working culture and employees' wellbeing in general. The situation over the last months (Jan.-Aug. 2020) has escalated due to Covid-19. Competition has been much fiercer. A fierce battle for customers and survival has begun. The owners have focused on streamlining and downsizing the company, with an impact on the intensive staff reductions. The situation of other major players in the international market is similar. While before the covid-19 pandemic, most employers competed to offer higher wages and better prospects, they are now focusing on redundancies and wage cuts. Everyone is trying to survive in the global market. In response to global consequences of Covid-19, the turnover of the company fell by $43 \%$ (1st, 2 nd quarter 2020). This is the reason why there is a need to intensively support sales executives' motivation to meet new sales goals and positively influence their engagement in making business all over the world, and thus globally improve the corporate performance. Competitive challenges and current financial and human resource issues bring a question how reward strategies could be developed which would support the achievement new strategic objectives such as: maintain market share, operate more efficiently, provide better and higher quality services to customers, develop a culture which is more adaptive and flexible in the face of new demands, improve the quality of staff, improve staff morale generally, value staff according to their contributions and develop a more attractive employment proposition to attract and retain high-quality staff. This paper is focused on determination of employee satisfaction with rewards, motivation and determination whether there is any link between reward satisfaction and achieved performance. This paper includes two research questions: 1) What level of satisfaction with rewards do sales executives have in the surveyed company? 2) What socio-economic consequences does sales executives' reward attitude have on their sales performance in the surveyed company?

\section{Results and discussion}

Based on the questionnaire survey, the following results were found. $57.1 \%$ of respondents think their contribution is not adequately rewarded. $71.4 \%$ of respondents think pay increases are not handled fairly. $64.3 \%$ of respondents feel that their pay does not reflect their performance. $64.3 \%$ of respondents opine their pay does not compare favourably with what they could get elsewhere. $64.3 \%$ of respondents feel they are not paid fairly in comparison with other people doing similar work in the organization. $78.6 \%$ of respondents think the organization's pay policy is overdue for a review. Only $35.7 \%$ of respondents agree that grading decisions are made fairly. It is not clear for $71.4 \%$ of 
respondents how decisions about their pay are made. This is not understandable for $74.1 \%$ of respondents how their job has been graded. Only $35.7 \%$ of respondents get good feedback about their performance. It is not clear for $64.3 \%$ of respondents about what they are expected to achieve. Despite of this $92.1 \%$ respondents like their job. $71.4 \%$ of respondents doesn't think the current performance pay scheme encourages better performance. The current performance pay scheme is meant as an annual bonus based on the Society's performance. There is no individual performance-related pay, but all staff are eligible for an annual bonus based on the Society's performance. Results show $71.4 \%$ of respondents are proud to work for the organization. Unfortunately, $78.6 \%$ of respondents do not understand how their pay can progress. $42.9 \%$ of respondents think job evaluation works fairly. The benefits package does not compare well with those in other organizations for $85.7 \%$ of respondents and $100 \%$ of respondents replied that they would like more choice about the benefits they receive. Only $28.6 \%$ of respondents feel motivated after their performance review meeting. And the pay policy of the organization is easy to understand for $50 \%$ of respondents.

On the base of collection of all these answers, the matrix of reward attitude survey was created which is shown in the table 1 . There is defined a sample of respondents $X=\left\{X_{1}, X_{2}\right.$, $\left.\ldots, \mathrm{X}_{14}\right\}$ whose total level of satisfaction is evaluated by their answers to the questions in the survey $Y_{1}, Y_{2}, \ldots, Y_{20}$. According to answers results $(y e s=1$, no $=0$ ) each respondent $X_{1}, i=1,2, \ldots, 14$ is described by a vector of values $\left(y_{i l}, y_{i 2}, \ldots, y_{i k}\right)$. Each reply has the same significance factor in other words the same weightings. According to the type of the question there are both type of criteria MAX/MIN which have impact on the calculation of the total satisfaction level. This table also contains turnover and margin achieved by each respondent to express their individual performance. The intention is to determine if there is any link between the level of satisfaction with the rewards and the achieved sales performance.

Table 1. Matrix of reward attitude survey - respondents' answers $-(\mathrm{Yes}=1, \mathrm{No}=0)$.

\begin{tabular}{|c|c|c|c|c|c|c|c|c|c|c|c|c|c|c|c|c|c|c|c|c|c|c|c|c|}
\hline \multirow{2}{*}{\multicolumn{2}{|c|}{\begin{tabular}{|l|} 
Question \\
Min/Max
\end{tabular}}} & 1 & 2 & 3 & 4 & 5 & 6 & 7 & 8 & 9 & 10 & 11 & 12 & 13 & 14 & 15 & 16 & 17 & 18 & 19 & 20 & \multirow{2}{*}{$\begin{array}{l}\text { Satis- } \\
\text { faction }\end{array}$} & \multirow{2}{*}{$\begin{array}{l}\text { Turn } \\
\text { over }\end{array}$} & \multirow{2}{*}{$\begin{array}{c}\text { Marg } \\
\text { in }\end{array}$} \\
\hline & & Max & Max & Min & Max & Min & Min & Max & Min & Max & Max & Max & Max & Max & Max & Max & Max & Max & Min & Max & Min & & & \\
\hline \multirow{8}{*}{ 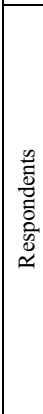 } & 2 & 0 & 0 & 1 & 0 & 1 & 1 & 1 & 1 & 0 & 0 & 0 & 1 & 0 & 0 & 0 & 0 & 0 & 1 & 0 & 0 & 3 & 17 & 28 \\
\hline & 4 & 0 & 0 & 1 & 0 & 1 & 0 & 0 & 1 & 0 & 0 & 0 & 1 & 0 & 1 & 0 & 0 & 0 & 1 & 0 & 1 & 3 & 45 & 18 \\
\hline & 5 & 1 & 0 & 1 & 0 & 1 & 0 & 0 & 1 & 0 & 0 & 0 & 1 & 0 & 0 & 0 & 1 & 0 & 1 & 0 & 0 & 5 & 53 & 26 \\
\hline & 8 & 1 & 1 & 0 & 1 & 0 & 1 & 1 & 1 & 1 & 1 & 0 & 1 & 0 & 1 & 0 & 1 & 0 & 1 & 0 & 0 & 12 & 38 & 28 \\
\hline & 9 & 1 & 0 & 0 & 1 & 0 & 1 & 1 & 1 & 1 & 1 & 0 & 1 & 1 & 1 & 0 & 0 & 0 & 1 & 1 & 1 & 11 & 29 & 25 \\
\hline & 10 & 0 & 0 & 1 & 0 & 1 & 1 & 0 & 0 & 0 & 0 & 1 & 1 & 0 & 1 & 0 & 0 & 0 & 1 & 0 & 0 & 5 & 49 & 28 \\
\hline & 11 & 1 & 1 & 0 & 1 & 0 & 1 & 0 & 0 & 1 & 1 & 0 & 1 & 1 & 1 & 1 & 1 & 1 & 1 & 1 & 1 & 15 & 58 & 30 \\
\hline & 12 & 0 & 0 & 1 & 0 & 1 & 1 & 0 & 1 & 0 & 0 & 0 & 0 & 0 & 0 & 0 & 0 & 0 & 1 & 0 & 1 & 0 & 114 & 32 \\
\hline
\end{tabular}

Source: own processing

The maximal satisfaction score can be 20 points. The highest reached value in this sample is 17 points and the lowest reached value is alarming 0. According to Table 2. the average level of satisfaction with rewards in the sample is 7 points out of 20 . The spider graph which is part of the Table 2. shows a comparison of all sales executives in the sample. It enables a quick and clear comparison of the position of a certain respondent in three indicators (level of satisfaction [points], turnover [thousands EUR], margin [\%]) in relation to the best value achieved in the sample. 
Table 2. Satisfaction level and performance results - all respondents.

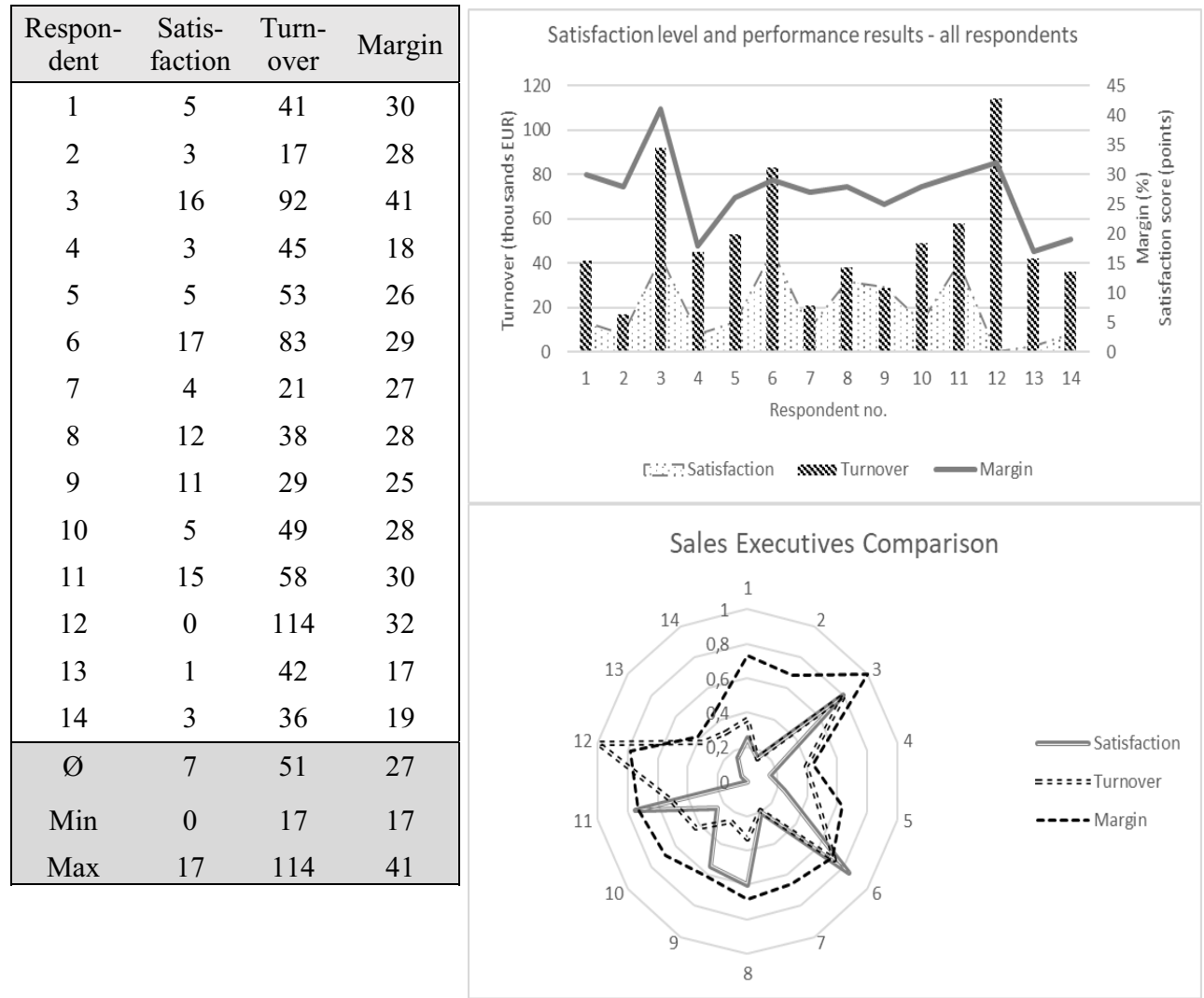

Source: own calculations

The sample of respondents was subsequently divided into two contingency tables, see the Table 3. One contains a group with a satisfaction score $\geq 10$ and the second one contains a group of respondents with a satisfaction score $\leq 9$ and their performance. As it can be found in the following figures, less satisfied sales executives predominate $(64.3 \%)$ in the business department. Initial observations suggest that there may be a link between satisfaction and performance. As results show only $35.7 \%$ of respondents are in this more satisfied group of sales executives and their average satisfaction score is 14 points, average turnover is 60 thousand EUR and average margin 30.6\%. Compared with the second group of dissatisfied sales executives representing $64.3 \%$ of sales executives in the sample we can find average satisfaction score only 3 points and lower average performance of both indicators: turnover 46 thousand EUR and margin $25 \%$. If we evaluate these two groups of dissatisfied and satisfied sales executives with each other, we can see that average performance results are clearly better in the group of more satisfied sales executives. These findings cannot be extrapolated to all respondents. However, this finding is only valid for the evaluation of the whole group. If we look at the specific results of individual sales executives, we can find that even a less satisfied employee has exceptionally good or even excellent performance results. The finding that a group with lower satisfaction score is less efficient can only be claimed as a generalization of a particular group. Results confirm that it does not mean some dissatisfied or unhappy sales executive cannot be more capable to reach far better performance results than some satisfied sales executive. So, it is not possible to express absolute certainty. There is some degree of uncertainty. 
Table 3. Respondents with satisfaction score $\geq 10$ vs. respondents with satisfaction score $\leq 9$.

\begin{tabular}{|c|c|c|c|c|c|c|c|}
\hline \multicolumn{4}{|c|}{$\begin{array}{l}\text { Respondents with satisfaction } \\
\text { score } \geq 10\end{array}$} & \multicolumn{4}{|c|}{$\begin{array}{l}\text { Respondents with satisfaction } \\
\text { score } \leq 9\end{array}$} \\
\hline $\begin{array}{c}\text { Respon- } \\
\text { dent }\end{array}$ & $\begin{array}{l}\text { Satis- } \\
\text { faction }\end{array}$ & $\begin{array}{l}\text { Turn- } \\
\text { over }\end{array}$ & $\begin{array}{l}\text { Mar- } \\
\text { gin }\end{array}$ & $\begin{array}{c}\text { Respon- } \\
\text { dent }\end{array}$ & $\begin{array}{l}\text { Satis- } \\
\text { faction }\end{array}$ & $\begin{array}{l}\text { Turn- } \\
\text { over }\end{array}$ & $\begin{array}{l}\text { Mar- } \\
\text { gin }\end{array}$ \\
\hline 3 & 16 & 92 & 41 & 1 & 5 & 41 & 30 \\
\hline 6 & 17 & 83 & 29 & 2 & 3 & 17 & 28 \\
\hline 8 & 12 & 38 & 28 & 4 & 3 & 45 & 18 \\
\hline 9 & 11 & 29 & 25 & 5 & 5 & 53 & 26 \\
\hline 11 & 15 & 58 & 30 & 7 & 4 & 21 & 27 \\
\hline \multirow[t]{5}{*}{$\varnothing$} & 14,2 & 60 & 30,6 & 10 & 5 & 49 & 28 \\
\hline & & & & 12 & 0 & 114 & 32 \\
\hline & & & & 13 & 1 & 42 & 17 \\
\hline & & & & 14 & 3 & 36 & 19 \\
\hline & & & & $\varnothing$ & 3 & 46 & 25 \\
\hline
\end{tabular}

Source: own calculations

To avoid making over generalizations it is necessary to say that some small number of exceptions exist also in this sample of respondents who have better performance despite the extremely low satisfaction score. A possible explanation for this might be that despite of the low satisfaction score the concreate employee may simply enjoy his/her job and his/her work can bring a pleasure and a fun for its meaningfulness and these characteristics of job may be preferred by the employee over the financial satisfaction. But question is how long time so that the company does not lose efficient and talented employees. The discrepancies between financial satisfaction score and performance results could be attributed to the fact that each sales executive manages a different sales area with a different sales conditions and manages fully customized projects which may affect turnover and margin.

\section{Conclusion}

Case is about organization where the development or improvement of reward management policies and practices is necessary to enhance organizational performance, and where there are specific issues and problems concerning current reward management practices which need to be dealt with.

The main goal of the current study was to determine what level of satisfaction with rewards do sales executives have in the surveyed company and to investigate the effects of socio-economic consequences of sales executives' reward attitude on their sales performance.

The questionnaire survey as a quantitative method of public opinion research was used for determining employee satisfaction and reward attitude. Statistical analysis was performed using SPSS software. Results were processed using frequency and contingency tables, graphs, and verbal description.

This study has identified that the average sales executives' satisfaction score in the sample is only 7 points out of 20 . The experiment confirmed that dissatisfied sales executives predominate in the sample. $64.3 \%$ of sales executives belong to the group of employees dissatisfied with rewards. This group includes respondents with satisfaction 
level $\leq 9$ points. The reward attitude survey undertaken here, has extended knowledge of sales executives' satisfaction level which can be interesting for company management and for other relevant decision makers. The findings from these studies suggest that employees' financial well-being and reward satisfaction can have an effect on individual performance results and thus can have globally positive effect on the corporate performance and can improve it. Sales executives having a higher satisfaction score belonged to the group showing higher average values of performance indicators than the group of dissatisfied sales executives. To avoid making over generalizations it is necessary to say that a few sales executives had better performance despite the extremely low satisfaction score. This can be explained in some exceptions by the predominance of positive feelings from job satisfaction over financial satisfaction. The consequences of low sales executives' financial well-being can be a significant reduction or lost productivity and motivation to achieve business goals when there is no individual performance-related pay. The administrative staff in the company is eligible for an annual bonus based on the Society's performance, but individual contribution and performance is not reflected there. Business managers, globally sales executives operating worldwide, representing brands and good reputation of international companies are a special group of staff needing especially flexible working conditions to do their job all over the world [23]. The evaluation and rewarding of their performance are globally linked to achieving business targets [23]. The data reported here appear to support the assumption that reward attitudes and financial well-being can be key drivers to attract and retain the sales executives the organization needs. Because low rewards satisfaction and low financial well-being significantly reduce the quality of life of most employees and affects both work and leisure. Such limitations in their lives can have psychological, social, and socio-economic consequences. According to this survey in the given sample of respondents among sales executives with low rewards satisfaction, approximately $88 \%$ of respondents stated that their dissatisfaction has a significant effect on their daily activities. The dominant presence of dissatisfied sales executives may also have major economic consequences for the company, as it reduces work engagement, enthusiasm, and productivity, and increases the number of employees with burnout. Monitoring the level of satisfaction of employees by employers is often neglected or even downplayed. The finding that employees are not satisfied with the reward and well-being can be rationally expected. But it is crucial for an organization to find out if their employees are more or less dissatisfied with their financial well-being and working conditions than employees of competing companies to avoid losing qualifying and talented employees. A key HR policy priority should therefore be to plan for the long-term care of employees and ensuring appropriate systems, services, and support.

Further work which needs to be done is to ensure that benefits, prospects and pay will be in such a competitive level of market price that will attract and retain the people the organization needs for retaining current global business operations and for searching new business challenges around the world. In the current global market situation with financial consequences of Covid-19 there can be very probably expected limitations to enforce any rewards support or satisfaction improvements. This will likely cause a major limitation of other work on the project.

The paper was supported within the project of the Student Grant Competition at the Faculty of Economic VŠB-Technical University of Ostrava SP2020/33.

\section{References}

1. Armstrong, M., Stephens, T. (2005). A Handbook of Empleyee Reward Management and Practice. London: Kogan Page Limited. 
2. Pfeffer, J. (1998). Six dangerous myths about pay. Harvard business review, 76(3), 109-120.

3. Gupta, N., \& Shaw, J. D. (1998). Let the evidence speak: financial incentives are effective!!. Compensation \& Benefits Review, 30(2), 26-32.

4. Gupta, N., \& Jenkins Jr, G. D. (1996). The Politics of Pay: Who gets what is often a matter of who is the better game player than of who really deserves more pay. You cannot overlook political dynamics if you want your company's compensation system to be effective. Compensation \& Benefits Review, 28(2), 23-30.

5. Lawler, E. E. (1990). Strategic Pay: Aligning Organizational Strategies and Pay Systems. San Franciso: Jossey-Bass.

6. Klontz, B. T., Bivens, A., Klontz, P. T., Wada, J., Kahler, R. (2008). The treatment of disordered money behaviors: Results of an open clinical trial. Psychological Services, 5(3), 295-308.

7. Dew, J. P., Stewart, R. (2012). A fnancial issue, a relationship issue, or both? Examining the predictors of marital fnancial confict. Journal of Financial Therapy, 3(1), 4 .

8. Selenko, E., Batinic, B. (2011). Beyond debt. A moderator analysis of the relationship between perceived fnancial strain and mental health. Social Science \& Medicine, 73(12), 1725-1732.

9. Sweet, E., Nandi, A., Adam, E. K., McDade, T. W. (2013). The high price of debt: Household fnancial debt and its impact on mental and physical health. Social Science \& Medicine, 91, 94-100.

10. Loban, Heron. (2011). Indigenous Consumers, Financial Stress and Emotional Wellbeing. Aboriginal, 35(6), 14-16.

11. MCCOY, M. (2020). Introduction to the Special Issue on the Intersection of Finances and Overall Well-Being. Contemporary Family Therapy: An International Journal, 42(1), 2-4.

12. Syrén, S. M., Kokko, K., Pulkkinen, L., Pehkonen, J. (2020). Income and Mental WellBeing: Personality Traits as Moderators. Journal of Happiness Studies. 21(2), 547-571.

13. Lucas, L., Vanderhei, J. (2019). Employer Approaches to Financial Wellbeing Solutions. EBRI Issue Brief, (491), 6-33.

14. Benitez, M., Peccei, R., Medina F. J. (2019). Employee well-being profiles and service quality: a unit-level analysis using a multilevel latent profile approach. European Journal of Work and Organizational Psychology, 28(6), 859-872.

15. Peccei, R. E., Van de Voorde, F. C., \& Van Veldhoven, M. J. P. M. (2013). HRM, well-being and performance: A theoretical and empirical review. HRM \& performance, $15-46$.

16. Hager, F. W. (2018). The Links between Meaningfulness of Work, Work-Engagement and mental Well-Being. In 14th Annual International Bata Conference for Ph. D. Students and Young Researchers, 76-94.

17. Passmore, J. (2019). Mindfulness in organizations (Part 2): a practitioners' guide to applying mindfulness-based approaches in leadership development, workplace wellbeing and coaching. Industrial and commercial training, 51(3), 165-173.

18. Ghazali, M. S., Alwi, S. F. S., Aziz, N. N. A., Hazudin, S. F. (2020). Pathway to Financial Well-being: A review on the role of psychological factors. EnvironmentBehaviour proceedings Journal, 5(13), 55-61.

19. Celma, D., Martinez-Garcia, E., Raya, J. M. (2018). Socially responsible HR practices and their effects on employees' wellbeing: Empirical evidence from Catalonia, Spain. European Research on Management and Business Economics, 24(2), 82-89. 
20. Liu, Y. P., Cooper, C. L. Tarba, S. Y. (2019). Resilience, wellbeing and HRM: a multidisciplinary perspective. International Journal of Human Resource Management, 30(8), 1227-1238.

21. Bui, H. T. M., Liu, G., Ko, W. W., Curtis, A. (2020). Harmonious workplace climate and employee altruistic behavior: from social exchange perspective. International Journal of Manpower, 1-34.

22. Koiol, W., Mikos, A. (2020). The measurement of human capital as an alternative method of job evaluation for purposes of remuneration. Central European Journal of Operations Research, 28(2), 589-599.

23. Polakova, G. (2020). Evaluation of Globally Operating Salesforce Staff by Multiple Attribute Decision Making Methods. In International Scientific Conference Globalization and its Socio-economic Consequences 2019 - Sustainability in the Global-Knowledge Economy, 74, 06025. 